William P.S. McKay MD FRCPC, William H. Noble MD FRCPC

\title{
Critical incidents detected by pulse oximetry during anaesthesia
}

The Critical Mcident Technique was used to study anaestherics given in a majar tertiary care teaching hospital in order to define indications for monitoring with a pulse oximeter during anaesthesia. Anaesthetists were asked to use a pulse aximeter in every case and trained to report Critical Incidents in order to determine if the oximeter can shorten the time to detection of these evenis. Four thousand seven hundred and ninety-seven anaestherics were given during a four-month period in 1986-87. A Critical Incident was recorded when an unexpected physiologic deterioraion requiring intervention by the ancesthetist to prevent a likely bad outcome was signalled first by the pulse oximeter. Critical Incidents were classiffed by patiest characteristics, physiologic change, type of anaesthetic, and the type. length, and place of surgery. Reports were received in 65 per cent of cases, and a Critical Incident occurred in 191 (six per cens) of these. Desaturation was the commonest physiologic change (15I) and was further classified as to severity (mild 85-94 per cent saturation, moderate 75-84 per cent. and severe 75 per cent). Desaturations during the maintenance phase of anaesthesia were milder but more frequent than those in the induction or emergence phases. There were no severe desaturations in elderly patients or those receiving regional anaesthesia. No group was free of Critical Incidents. Since undetected hypoxaemia may lead to disastrous complications we recommend that a pulse aximeter be used for every anaesthetic.

\section{Key words}

MEASUREMENT TECHNIQUES: oximetry; OXYGEN: saturation, blood levels; ANAESTHETIC TECHNIQUES: general, regional.

From the Department of Araesthesia, St. Michuel's Hospital, University of Toronto, Toronto, Ontario.

Address correspondence to: Dr. William H. Noble, Department of Anaesthesia, St. Michael's Hospital, 30 Bond St., Toronto, Ontario M5B 1 W8.

Presented at the 1987 Annual Meeting of the Canadian Anaesthetists' Society, Calgary, Albcrta.
The pulse oximeter is a convenient, automatically caljbrated, non-invasive clinical monitor of oxygen saturation and pulsation. Its accuracy and reliability ${ }^{1,2}$ have been studicd in the respiratory physiology laboratory, ${ }^{3}$ intensive care unit, ${ }^{4}$ operating room ${ }^{5,6}$ (OR), and recovery room ${ }^{7,8}$ Only a small number of confounding factors (IV dyes, ${ }^{9}$ strong incident light, especially heat lamps, ${ }^{10}$ and abnormal haemoglobins ${ }^{11}$ ) have been found. The greatest value of the oximeter is its ability to provide an early waming of hypoxaemia. Clear indications for its use have not been developed. At the Canadian Anaesthetists' Society Annual Meeting in 1986, a panel of experts (S.G. Neil, A.M. Lam, K.W. Tumbull, and K.K. Tremper; Panel on OR monitoring) was split on whether the information given by the oximeter offset the expense for routine use in the operating room. This study assesses the clinical usefulness of oximetry during anaesthesia by investigating when and where it shortens the time to detection of critical events.

\section{Methods}

The Critical Incident Technique (CIT) ${ }^{12-14}$ was used to identify and estimate the frequency of anaesthesia related incidents that might endanger the patient. Cooper et at. showed that the CIT performed these functions well in the anaesthesia setting. ${ }^{17,14}$

During a four-month period (October 1986 to February 1987) all inpatients and outpatients having anaesthetics at a major tertiary care teaching hospital were included in a prospective study. Patients having epidural analgesia for labour and delivery were excluded. All patients were routinely monitored with continuous ECG, temperature probe, and blood pressures determined every five minutes.

All members of the Anaesthesia Department were requested at a training session to use a Nellcor N-I00 oximeter in the O.R. throughout every case and to complete a questionnaire. Three questions were posed: (1) Was the oximeter applied? (2) Was it the first warning of an unexpected problem? (3) Did false alarms occur?

When (2) or (3) were answered positively, the chart was examined in detail and the anaesthetist interviewed within two days. A Critical Incident (CI) was recorded by 
the investigator if an unexpected physiologic change severe enough to require intervention by the anaesthetist to prevent a likely adverse outcome was signalled first by the oximeter. If both the investigator and the reporting anaesthetist agreed that the criteria were met, a CI was recorded. Physiologic changes which fit these criteria included oxygen saturation below 95 per cent, and changes in pulse, blood pressure, or temperature, which, given the patient's condition, could reasonably be expected to lead to a poor outcome. The process excluded expected physiologic changes (such as sinus tachycardia or hypertension due to light anaesthesia) corrected by ordinary anaesthetic adjustments.

We classified the Cls as to subjects' age, sex, smoking habits, ASA physical status, obesity, type of operating room suite (inpatient, outpatient, or obstetric ), type of surgery (abdominal, back, cardiovascular, head and neck, limb/peripheral, obstetrics, shared airway/endoscopy, thoracic), phase of surgery (induction, maintenance, or emergence), number of other monitors applied, and type of anaesthetic (regional or general). Obstetrical anaesthesia was defined as surgery on the reproductive tract of a woman in her third trimester. All our obstetrical cases were Caesarian sections. When desaturation created CIs, they were subdivided into mild (85-94 per cent saturation), moderate ( $75-84$ per cent), and severe ( $<75$ per cent).

An unexpected alarm in the absence of any physiologic change was recorded as a False CI. Confidentiality was assured for both patients and anacsthestists. The study was not sponsored by any commercial interest.

Chi-square analysis with a five per cent confidence level was used to compare the calegories of Cl's. Yate's correction was used where applicable.

\section{Results}

Four thousand seven hundred and ninety-seven cases were done (Table I). Cards were marked in 65 per cent of cases and response did not depend on type of OR suite

TABLE 1 Critical incidents

\begin{tabular}{lcccc}
\hline & Inparient & Outparient & Obstetric & Total \\
\hline Cases & 3384 & 1236 & 177 & 4797 \\
Cards marked & 2145 & 907 & 102 & 3154 \\
Response rate & $63 \%$ & $73 \%$ & $57 \%$ & $65 \%$ \\
Oximeter applied & 2115 & 887 & 98 & 3100 \\
Application rate & $98 \%$ & $97 \%$ & $96 \%$ & $98 \%$ \\
Cls & 149 & 28 & 14 & 191 \\
Cl rate & $7 \%$ & $3 \%$ & $14 \% \dagger$ & $6 \%$ \\
False CIs & 61 & 1 & 3 & 65 \\
False Cl rate & $2 \%$ & $0.1 \% *$ & $3 \%$ & $2 \%$ \\
\hline
\end{tabular}

- Significantly different from inpatient group.

† Significantly different from non-abstetric patients.
TABLE II Physiologic change signalled

\begin{tabular}{lr}
\hline Desaturation & 151 \\
Heart rhythm change & 45 \\
Temperaure decrcase & 7 \\
Blood pressure decrease & 4 \\
Blood pressure increase & 3
\end{tabular}

The oximeter was applied in 98 per cent of cases where cards were marked.

Desaturation was the most frequent physiologic change signalled (Table II). The ECG is monitored routinely in our OR's but alarms are not provided on some monitors or are not routinely set, so the oximeter was the first indicator of a poorly tolerated altered heart rhythm in 45 cases. Bradycardia was most frequent, followed by tachycardia, and other arthythmias. Temperature is also routinely monitored, without alams, and in seven long cases the oximeter was the first indication of a temperature $<35^{\circ} \mathrm{C}$. A potentially dangerous unexpected blood pressure drop occurred four times and in three cases severe unexpected hypertension caused a CI by signalling loss of pulsation.

There were 191 CIs (Table I), a rate of six per cent, with the rate for outpatients significantly lower than for inpatients, and that for obstetrical surgery significantly greater than for nonobstetric. The False $\mathrm{Cl}$ rate was two per cent, with significantly fewer in outpatients. There was at least a four per cent overall Cl rate, even if no Cl's occurred in cases with unmarked cards.

Cls occurred in every ASA physical class ( 53 in class I, 76 in II, 34 in III, and 28 in IV).

In each case of desaturation, a prinary cause and the most important contributing cause (Table III) were atrributed in consultation with the reporting anaesthetist. In 37 cases there was only one cause. Airway and intubation problems, including trouble maintaining a patient airway during use of mask were the commonest causes of desaturation, followed by lung disease and narcosis. Contributing causes included obesity first, then lung disease and then other illnesses such as heart disease, sepsis, or multisystem organ failure.

TABLE II]

\begin{tabular}{lll}
\hline Contifion & $\begin{array}{l}\text { Primary } \\
\text { cause (\%) }\end{array}$ & $\begin{array}{l}\text { Contributing } \\
\text { cause (\$) }\end{array}$ \\
\hline $\begin{array}{l}\text { Upper/lower airway spasm/oedema' } \\
\text { soft lissue obstruction }\end{array}$ & $37(19)$ & \\
$\begin{array}{l}\text { Lung discase } \\
\text { Narcosis }\end{array}$ & $29(15)$ & $22(11)$ \\
lntubation problem & $26(14)$ & \\
Obesity & $22(11)$ & $28(15)$ \\
Onher illness & & $\mathbf{2 0}(10)$ \\
\hline
\end{tabular}


TABLE IV Factors associated with severity of desaturation

\begin{tabular}{|c|c|c|c|}
\hline \multirow[b]{2}{*}{ Facror } & \multicolumn{3}{|c|}{ Desaluration } \\
\hline & $\begin{array}{l}\text { Mild } \\
85-94 \%\end{array}$ & $\begin{array}{l}\text { Moderate } \\
75-84 \%\end{array}$ & $\begin{array}{l}\text { Severe } \\
<75 \%\end{array}$ \\
\hline Total & 80 & 42 & 29 \\
\hline \multicolumn{4}{|l|}{$\mathrm{AgC}$} \\
\hline$-<40$ yr & 29 & 14 & 14 \\
\hline$-40-70 y r$ & 36 & 20 & 15 \\
\hline$->70 \mathrm{yr}$ & 15 & 8 & $0^{*}$ \\
\hline Obesity & 24 & 17 & 9 \\
\hline Smoking & 27 & 17 & 10 \\
\hline \multicolumn{4}{|l|}{ ASA Class } \\
\hline- I-II & 52 & 24 & 13 \\
\hline - III-IV & 20 & 10 & 7 \\
\hline \multicolumn{4}{|l|}{ Phase } \\
\hline - Induction & 21 & 16 & 12 \\
\hline - Maintenance & $48 \dagger$ & 14 & 10 \\
\hline - Emergencc & 11 & 12 & 7 \\
\hline \multicolumn{4}{|l|}{ Anaesthetic } \\
\hline - General & 71 & 41 & 29 \\
\hline - Regional & 9 & 1 & of \\
\hline
\end{tabular}

* Significantly different from all other ages and degrees of saturation. † Significantly different from all other phases and degrees of saturation. $\ddagger$ Significantly different from general anaesthetic.

The distribution of "factors" (Table IV) associated with mild, moderate, and severe desaturations were compared with the "total" distribution. Age did not predict a more severe desaturation; on the contrary, none of the 23 geriatric patients who desaturated reached the severe level. Obesity appeared to be a risk factor for desaturation (Table III), but did not predict severity (Table IV). Unexpected desaturations happened more often during the maintenance phase but were more often mild than during induction or emergence.

General anaesthesia was associated with all the severe desaturations (29), and this was significantly different from regional anacsthesia. There was not a higher proportion of geriatric patients given regional anaesthesia. The following factors did not predict severity of desaturation: sex, length of operation, smoking, obesity, type of surgery, ASA class, or number of additional monitors applied.

\section{Discussion}

The pulse oximeter consists of a probe, a small dedicated computer, and a cable connecting the two. ${ }^{15}$ The probe may be clipped on a finger-tip, toe, nose, or ear (any of these sites was used for OR monitoring if it produced a strong pulse signal and registered the correct pulse rate, although subtle differences have becn shown between finger and ear in pulse volume ${ }^{16}$ and in saturation during heavy exercis ${ }^{3}$ ). The probe transmits rapidly alternating beams of red light at two wavelengths through the patient's appendage to a photo cell which transmits pulsatile signals to the computer. The pulse and saturation are derived, based on the differential absorption of the two wavelengths by saturated and reduced hacmoglobin at successive times during the pulsation of arterial blood into the tissue. Adjustable alarms warn of high or low pulse rate or saturation level and of biood pulsations insufficient for proper functioning of the device. A "beep" is sounded for each pulse detected and the pitch of the "beep" vuries with the saturation. Pulse rate and saturation are also displayed visually. Tytler ${ }^{4}$ found the pulse oximeter accurate within one digit $( \pm 1.0 \%)$ of a laboratory in vitro oximeter. Yelderman and $\mathrm{New}^{1}$ studied healthy volunteers breathing at low $\mathrm{FIO}_{2}$ and found a high correlation $(\mathrm{R}=0.98)$ with in vitro saturation. We considered it unethical to pause during a critical incident to draw arterial blood for blood gas analysis where it would not be clinically indicated (in the midst of an airway problem, upon discovering and before correcting a disconnection, etc) and relied upon five assurances of the specificity of an hypoxic waming. First, all the cited studies ${ }^{l-11}$ show that if the pulsations are indicated as sufficient, and the indicated pulse rate matches the patient's, the oximeter only indicates hypoxia falsely in the presence of the cited rare confounding factors. These did not occur in our study. More importantly, three criteria were met in every case. First, all patients had a normal saturation prior to induction; second, all had a problem which explained the desaturation; third, all reverted to a normal saturation when the problem was corrected. Finally, where blood gas assays were clinically indicated they inevitably corroborated the oximeter.

Reported false CIs (Table I) were caused by surgical cautery, cable disconnect, and movement of the probe.

The CIT is a problem solving technique, not a descriptive science. It relies on reports of relatively infrequent events (anecdotes) which conventional science discards by measures of central tendency. The exact quantification of events pursued by conventional scientific measurement is imposşible in a method which must rely on reporters' cooperation, memory, judgement, understanding, and ongoing interest in the study. However, the CIT has been repeatedly validated ${ }^{17}$ and found to be useful in anaesthesia studies. ${ }^{13,14}$

Objectivity, as measured by inter-observer agreement, has been shown to be best when certain conditions are met. ${ }^{12}$ (1) The situation/behaviour to be reported should be strictly specified. We limited the situation to surgical anaesthesia and specified the behaviour: anaesthetist's response to an oximeter alarm. (2) The reporting is clearly relevant to the aim of the activity under investiga. tion. Our reporters (anaesthetists) considered the study 
important to the aim of patient safety. (3) The events reported have a major effect on the aim of the activity. The potential dangers of Cls as defined are well known. (4) The reporters selected are familiar with the activity. Anaesthetists were chosen as reporters for this study rather than, for example, clerical staff. (5) The reporters are trained in the collection of Cls. We provided daily "training" in the form of frequent informal coaching as well as the initial training session.

A test of sample size adequacy ${ }^{12}$ was also applied. After classification of the first $50 \mathrm{Cls}$ into types of incidents, subsequent CIs should generate fewer than five new classes per 100. Otherwise, additional sets of $100 \mathrm{Cls}$ should be collected until a set requires fewer than five new classes. All types of CIs found in the last 100 incidents in our study were represented in the initial 50 . Therefore the sample size is adequate to allow conclusions.

While the CIT cannot provide us with the true number of Cls that occurred during the study, it has the advantage of permitting study of a large data base of relatively rare events (like bypoxia) inexpensively.

If the investigator can be reasonably assured that the study is free of spurious reports (we checked the chart and interviewed the anuesthetists), it can be said that CIs have at least a certain frequency. Then judgement must be used to decide if that rate is a significant problem (or benefit) with respect to the stated goal of the activity studied. In our case patient safety was the goal of interest in the activity $O R$ anaesthesia. If the oximeter shortens the time to detection of a correctable Cl, particularly hypoxia, then organ damage will likely be decreased, and we would expect that in a larger sample population bad outcomes will be avoided. The rates of Cls uncovered in this study represent significant patient problems with potentially bad outcomes.

No group of patients was immunc from Cls, regardless of ASA physical status category, type or length of surgery, surgical suite (inpatient, outpatient or obstetrics), or type of anaesthetic (general or regional). Obstetrics patients were at greatest risk for a CI.

That no severe desaturation occurred in the elderly patients is a surprise and possibly indicates that they are anaesthetized as cautiously as the very ill but were in fact not very ill.

Regional anaesthesia was no protection from a $\mathbf{C I}$, but appears to protect from severe desaturation. The small number of cases does not allow a firm conclusion.

The False CI rate was lowest in outpatients $(\mathrm{p}<0.05$ ) Thus, the oximeter was least troublesome in the patients with fewest problems. None of the anaesthetists involved considered the oximeter a time-consuming, troublesome, or distracting monitor.

We did not formally study how often other monitors warned before the oximeter, but this appeared to happen rarcly.

Cooper's reporters failed to retum questionnaires for 30 per cent of patients. ${ }^{8}$ The 35 per cent of our cases with unmarked cards may contain cases done by: (a) anaesthetists who are fearful of reporting their practices and who have more CIs than the others; (b) the same incidence of $\mathrm{CIs}$ in cases where the anaesthetists simply forgot to respond; (c) fewer CIs and anaesthetisls who forgot to respond because nathing went wrong. The last of these gives the lowest possible CI rate, four per cent. No anaesthetist objected to the study or refused to report; on the contrary, those who forgot to report were always apologetic. We conclude that the oximeter gives the earliest warning of events which increase risk during anaesthesia in at least four per cent of cases and that no group of anaesthestized patients is immune to these risks.

Cooper $e t a l$, in a study intended to devise and test an indirect measure of quality of anaesthetic care, found fewer anaesthetic complications pertinent to recovery room care ${ }^{8}$ in the final period of their study when a pulse oximeter was used. However, their data show gradual overall decline in these clinical complications, and Cooper et al. state that confounding factors make it impossible confidently to credit the decline to the oximeter.

Our study does not determine if complications are decreased by the oximeter, but shows that in four per cent of cases the time to discovery of an increased risk of complication is shortened. This use of a more sensitive measure than Cooper's explains our more definite findings.

The Canadian Medical Protective Association settles three to five hypoxia related cases per year at over $\$ 1 \mathrm{M}$ each.* Assuming only a five-year lifespan for a $\$ 6000$ oximeter and a generous 20 per cent annual repair bill, it costs $\$ 2400 /$ year to equip an OR with this monitor. For an OR doing 20 cases per week for 50 weeks a year, it costs $\$ 2.40$ per case for monitoring with pulse oximetry

\section{Recommendations}

We have shown that every anaesthetic in every group of adult patients for all kinds of surgery in inpatient, outpatient, or obstetrical settings carries the risk of a patient hazard such as hypoxia that is first detected by the pulse oximeter. Since the worst outcomes (cerebral hypoxia for example) depend upon severity and duration of hypoxia, early detection of problems by an oximeter should be of great practical benefit in preventing these disasterous results. Hypoxia is associated with the most tragic and costly outcomes of anaesthesia and is the only physiologic change poorly detected by other means. ${ }^{18,19}$ Clinical signs are not as sensitive as the oximeter in

*A. Dunn, Toronto, Ontario, personal communication. 
detecting hypoxia. Arterial blood gas analysis is intermittent and results are not usually immediately available. Therefore an oximeter should be available for every $O R$, and, in addition to conventional monitors, should be used in every case.

\section{Acknowledgements}

We thank the anaesthetists of St. Michael's Hospital, University of Toronto, for their cooperation and assistance.

\section{References}

1 Yelderman $M$, New $W J r$. Evaluation of pulse oximetry. Anesthesiology 1983; 59: 349

2 Tayler MB, Whitwam JG. The current status of pulse oximetry. Anaesthesia 1986; $41: 943$.

3 Hanien JE, Casaburi R. Validity of ear oximetry in clinical exercise testing. Chest 1987; 91: 333.

4 Tytler JA, Seeley $H F$. The Nellcor N-101 Pulse Oximcter a clincal evaluation in anaesthesia and intensive cure. Anaesthesia 1986; 41 : 302.

5 Barker SJ, Tremper KK, Gamel OM. A clinical comparison of transcutanenus $\mathrm{PO}_{2}$ and pulse oximetry in the operating room. Anesth Aralg 1986; $65: 805$.

6 Dorles JC, Nijboer JA. Photo-electric plethysmograpby as a monitoring device ir, anaesthesia. Br J Anaesth 1985; 57 : 524.

7 Tyler IL, Boonrak T, Winter PM, Etsuro KM. Continuous monitoring of artcrial oxygen saturation with pulse oximetry during transfer to the recovery room. Anesth Analg 1985; 64: 108.

8 Cooper $J B$, Cullen DJ, Nemeskal $R$, et al. Effects of information feedback and pulse oximetry on the incidence of anesthesia complications. Anesthesiology 1987; 67: 686.

9 Side A, Rush WR, Paulus DA, Gravenstein N, Davis RF. Effect of fluorescein, indocyanine green and methylene blue on the measurement of oxygen saturation by pulse oximetry. Anesthesiology 1986; 65: A132.

10 Brooks TD. Paulus DA, Winkle WE. Infrared heat lamps interfere with pulse oximeters. Anesthesiology 1984; 61 : 630.

11 Ries AL. Oximetry - know thy limits. Chest 1987;91 316.

12 Flanagan $J C$. The critical incident technique. Psychological Bulletin 1954; $51: 327$.

13 Cooper JB, Newbower RS, Long CD, McPeek B. Preventable ancsthesia mishaps: A study of human factors. Anesthesiology 1978; 49: 399.

14 Cooper JB, Newbower RS, Kitz RJ. An analysis of major crrors and equipment failures in anesthesia manage ment: considerations for prevention and detection. Anesthesiology 1984; 60: 34 .
15 Yoshiya I, Shimada Y, Tanaka K. Spectrophotometric monitoring of arterial oxygen saturation in the fingertip. Med Biol Eng Comput 1980; 18: 27

16 Nijboer JA, Dorlas JC. Comparison of plethysmograms taken from finger and pinna during anaesthesia. $\mathrm{Br} J$ Anaesth 1985; 57: 531.

17 Andersson $B$, Nilsson S. Studies in the reliability and validity of the critical incident technique. J Appl Psychal 1964; $48: 398$.

18 Kelman $G R, N u n n J F$. Clinical recognition of hypoxemia under fluorescent lamps. Lancet 1966; 1: 1400.

$19 \mathrm{Knill} R L$. Evaluation of arterial oxygenation during anaesthesia. Can Anaesth Soc J 1985; 32: S16.

\section{Résumé}

La technique des incidents critiques (Critical Incident Technique) était utilisée afin d'étudier les agents anesthésiques administres dans un centre hospitalier tertiaire d' enseignemen afin de definir les indications d'une surveillance avec un saturomèrre (pulse oximeter) durant l'anesthésie. Les anesthésiologistes devaient utiliser le saturomètre dans chaque cas et devaient être entraînés à rapporter les incidents critiques afin de déterminer si l'axymètre pouvait diminuer le temps de dérectian de ces incidents. 4797 anesthésies furent administrées durant quatre mois en 1986-87. Un incident critique est enregistré aussitôt quand on détectait avec le saturomètre une détérioration phvsiologique subite requérant l'inservention de l'anesthesiologiste pour prévenir la possibilité d' une complication. Les incidents critiques étaient classifiés d'après les caractéristiques du patient, les changements physiologiques, le type d'anesthésie et le type, la durée, et piace de la chirurgie. Les rapports ont été reçus dans 65 pour cent des cas et un incident critique est survenu dans 191 ( six pour cent) de ceux-ci. La désaturation était le changement physiologique le plus commun (ISI) et elle fut de plus classifiée selon sa sévérité llégère 85 d 94 pour cent saturation, madérée 75-84 pour cent. et sévére $<75$ pour cent). Les désaturations durant lo phase de maintien de l'anesthésie étaient légères mais plus fréquentes que celles qui sont sunvenues lors de l'induction ou de la phase de l'émergence. On a noté aucune désaturation sévère chez les patients ágés et chez ceux subissant une anesthésie régionale. Aucun groupe n'étair libre d'incident critique. Etans donné que Ihypoxémie non détecrée peut aboutir à des complications désastreuses on recommande que le saturomètre soit utilisé avec. chaque administration de l'anesthésie. 